\title{
Chemical and thermal stratification in lakes
}

$\operatorname{AUTHOR}(S)$ :

Yu, Hui; Tsuno, Hiroshi; Hidaka, Taira; Jiao, Chunmeng

\section{CITATION:}

Yu, Hui ... [et al]. Chemical and thermal stratification in lakes. Limnology 2010, 11(3): 251-257

ISSUE DATE:

2010-12

URL:

http://hdl.handle.net/2433/126725

\section{RIGHT:}

The original publication is available at www.springerlink.com; This is not the published version. Please cite only the published version.; この 論文は出版社版でありません。引用の際には出版社版をご確認ご利用 ください。 


\section{Chemical and thermal stratification in lakes}

Hui Yu(a), Hiroshi Tsuno (b), Taira Hidaka (b, *) and Chunmeng Jiao(c).

(a) Chinese Research Academy of Environmental Sciences, 8 Dayangfang BeiYuan Road., Chaoyang District, Beijing 100012, China

(b) Department of Urban and Environmental Engineering, Graduate School of Engineering, Kyoto University, Kyoto-Daigaku-Katsura, Nishikyo-ku, Kyoto 615-8540, Japan

(c) Lake Biwa Environmental Research Institute, 5-34 Yanagasaki, Otsu 520-0022, Japan

Total text page: 10

Numbers of tables: 0

Numbers of figures: 7

*Corresponding author. Tel./fax: +81-75-383-3350/3351; E-mail: hidaka@water.env.kyoto-u.ac.jp (Taira Hidaka) 


\section{ABSTRACT}

An index which shows chemical stratification strength (IC-i; i=water quality item such as Chl.a and SP) was proposed and compared with one of thermal stratification strength indices, Schmidt's Stability index (SSI), in Shiozu Bay and Lake Biwa, Japan. The proposed indices of IC-i can be easily calculated with at least one set of each water quality data in both the epilimnion and the hypolimnion. The SSI was shown to be consistent with the traditional thermocline index of Thermocline Strength Index (TSI), but SSI is used as the stability index of the whole lake, while TSI is used as the stability index near the thermocline. Analyses showed that chemical stratification strength is determined largely by thermal stratification strength. Totally different characteristics of IC-Chl.a and IC-PO 4 at high SSI in the main North Basin of Lake Biwa and in Shiozu Bay were possibly due to the difference in their volumes and hydrodynamic conditions. The proposed index and relationships are especially useful to discuss them roughly with only a few data available.

KEYWORDS stratification, thermocline strength, chemocline strength, index 


\section{Introduction}

Thermal stratification, one of the physical stratification mechanisms, develops in summer in middle and high latitude area, and affects vertical water quality distribution in lakes, especially in eutrophied lakes. As the surface waters are warmed and become less dense, the relative thermal resistance of mixing increases markedly. A difference of only a few degrees is then sufficient to prevent complete circulation (Wetzel, 2001). Several stability indices or numbers have been proposed, in which thermocline strength index (TSI) and Brunt-Vaisala frequency are very simple, as they are calculated by the maximum extent of thermal change with depth, and widely used in lakes (Horne and Goldman, 1994). Wedderburn Number (Imberger and Hamblin, 1982) is used to show the mixing stability. Lake Number (Imberger, 1990) characterizes the dynamic stability of lakes (Hondzo and Stefan, 1996). Richardson Number and Froude Number are used as indices for stability of bulk water body (Imberger and Patterson, 1990). Other indices, such as Schmidt's Stability index (SSI) (Schmidt, 1928; Idso, 1973) and Hutchinson's stability index (Hutchinson, 1957) are also widely used. These indices are meaningful to evaluate the physical stratification strength and discuss physical state and characteristics in lakes. In the epilimnion, primary production by phytoplankton accompanies with production of oxygen and consumption of nutrients. In the hypolimnion, nutrients are accumulated by organic matter falling from the epilimnion and by release from the sediment and degradation of organics with consumption of oxygen. As a result, vertical distributions of water quality, such as chlorophyll-a, nutrients, dissolved oxygen occur during stratification seasons. This phenomenon is called "chemical stratification", and the layer at which rapid change in substance occurs is called "chemocline" (Horne and Goldman, 1994). The chemical stratification is as important as thermal stratification in discussion of water quality state and its formation mechanism (Dunnivant, 2006). For example, in Lake Toba in Indonesia, thermal and chemical stratification conditions are totally different (International Lake Environment Committee, 1990). Some researchers are discussing thermal and chemical stratification in lakes and wetlands (Rimmer et al., 2005; Talling, 2006, Michael et al., 2006, Larson et al., 2007, Elçi, 2008). To discuss stratification in lakes, a lot of data obtained by survey of vertical profiles are essential, as widely used stratification indices are calculated by detailed data, but such data are not always available in lakes worldwide. Simpler indices which can be calculated with less data are helpful to discuss stratification in lakes where less data are available.

The purpose of this study was to propose a simpler index to discuss stratification in lakes, and verify its applicability. In this paper, a new chemical stratification index was proposed, and strength and characteristics of the chemical stratification were discussed in relation to thermal stratification using the data collected in Shiozu Bay and North Basin of Lake Biwa, the largest fresh water lake in Japan. Then relationships between thermal stratification and chemical stratification are discussed in terms of water quality formation mechanisms. 


\section{Indices of Chemical and Thermal Stratification}

Strength of chemical stratification associated with a water quality item is defined by the difference of concentrations of the item between the epilimnion and the hypolimnion. However the concentration difference is affected by the concentration level of the item depending on eutrophication state in each lake and on each item value. By taking these factors into consideration, following dimensionless chemical stratification index IC-i for water quality "i" was proposed. This is the ratio of the concentration difference to the average concentration in the epilimnion and the hypolimnion.

$$
\mathrm{IC}-\mathrm{i}=(\mathrm{CU}-\mathrm{i}-\mathrm{CL}-\mathrm{i}) /\{(\mathrm{CU}-\mathrm{i}+\mathrm{CL}-\mathrm{i}) / 2\}
$$

where, CU-i and CL-i are concentrations of water quality item "i" in the epilimnion and the hypolimnion, respectively. IC-i corresponds to the ratio of CU-i and CL-i or $\ln (\mathrm{CU}-\mathrm{i} / \mathrm{CL}-\mathrm{i})$ (Fig.1). The value of IC-i changes in the range from -2 when $\mathrm{CU}-\mathrm{i}=0$ to +2 when $\mathrm{CL}-\mathrm{i}=0$. The value of $\mathrm{IC}-\mathrm{i}$ is 0 when $\mathrm{CU}-\mathrm{i}=\mathrm{CL}-\mathrm{i}$ which means complete mixing and no stratification. The value of $\ln (\mathrm{CU}-\mathrm{i} / \mathrm{CL}-\mathrm{i})$ may also be a index of stratification. Because the values of CU-i and/or CL-i are sometimes 0 or too low, the value of $\ln (\mathrm{CU}-\mathrm{i} / \mathrm{CL}-\mathrm{i})$ becomes too small or large, therefore, $\ln (\mathrm{CU}-\mathrm{i} / \mathrm{CL}-\mathrm{i})$ is not suitable as a index. Especially, IC-i values have advantage when one of CU-i and CL-i are 0 or too low. If both CU-i and CL-i are 0 or less than the detection limits, IC-i value is assumed to be 0 , which means that there is no stratification.

Conventionally used TSI was compared with SSI which are calculated by equations (2) and (3), respectively.

$$
\mathrm{TSI}=\Delta T / \Delta h\left({ }^{\circ} \mathrm{C} / \mathrm{m}\right)
$$

where $\Delta T$ and $\Delta h$ are difference of water temperature in Celsius and water depth (m), respectively, between the upper and lower edges of the thermocline.

$$
\mathrm{SSI}=\frac{1}{A_{0}} \int_{Z 0}^{Z m} A_{z}\left(z-z_{g}\right)\left(\rho_{z}-\rho_{g}\right) d z \quad\left(\mathrm{~kg} \cdot \mathrm{m} / \mathrm{m}^{2}\right), \quad z_{g}=\frac{1}{\int_{Z o}^{Z m} A_{Z} \rho_{Z} d z} \int_{Z 0}^{Z m} A_{z} \rho_{z} z d z \quad(\mathrm{~m})
$$

where $A_{0}$ is surface area of lake $\left(\mathrm{m}^{2}\right), z$ is depth $(\mathrm{m}), z_{m}$ is maximum depth $(\mathrm{m}), z_{0}$ is water surface depth $(\mathrm{m}), A_{z}$ is area at depth $z\left(\mathrm{~m}^{2}\right), \rho_{z}$ is density at depth $z\left(\mathrm{~kg} / \mathrm{m}^{3}\right), \rho_{g}$ is density at depth $z_{g}\left(\mathrm{~kg} / \mathrm{m}^{3}\right), V$ is lake volume $\left(\mathrm{m}^{3}\right)$, and $z_{g}$ is depth to the center of gravity of stratified lake (m). In this study, density was calculated as a function of only temperature. 
Thermocline is recognized to exist when TSI $>1\left({ }^{\circ} \mathrm{C} / \mathrm{m}\right)$ and stratification strength becomes stronger with larger value of TSI (Horne and Goldman, 1994). SSI is a measurement of the water column stability and indicates the amount of mechanical work required to mix the lake to an isothermal condition. The value is zero when the water column is isothermal and maximum when the lake is most strongly stratified. This parameter comprehends whole lake conditions such as temperature profile and morphology, so it might be a suitable parameter to discuss thermal stratification and its relationship with chemical stratification. Because calculating SSI needs detailed information, few researchers have calculated SSI in Lake Biwa.

Chemical stratification strength becomes stronger or weaker than thermal stratification strength in correspondence to each water quality item by biogeochemical reactions and the physical actions except for the thermocline effects. The concept of relationship between chemical and thermal stratification is showed in Fig 2. Higher IC-i means strong chemocline with larger epilimnetic concentrations than hypolimnetic concentrations, and vice versa. When TSI and SSI are low, IC-i should be also low if the biogeochemical reaction effects are slower than mixing effects. If the biogeochemical reaction effects are faster than mixing effects, IC-i values can be far from 0 at even lower TSI and SSI. In the situation of higher TSI and SSI, whether IC-i is higher or lower means different biogeochemical reaction effects other than mixing between the epilimnion and the hypolimnion. While in the situation of higher TSI and SSI, IC-i of 0 means the biogeochemical reaction effects both in the epilimnion and in the hypolimnion other than mixing are the same, but the biogeochemical reactions could be different in the epilimnion and the hypolimnion. In fresh water lakes like Lake Biwa, the density stratification is primarily thermal and secondarily turbid (Okubo et al. 1998). Water column stability near the seasonal thermocline could be affected by intrusive turbid layers from turbid river floods, but the effects of these occasional events can be omitted because our research was conducted by biweekly data which overlooked these flood events and because the turbid flood effects become much weaker in the lake center where the data were collected.

\section{Study Site}

Two sets of data in Lake Biwa were used in this study. One was in Shiozu Bay collected in this research and the other was in the main North Basin of Lake Biwa collected by Shiga Prefecture, Japan (Shiga Prefecture, 2003; 2004) at the official monitoring stations(See Fig. 3). In Lake Biwa, electric conductivity difference between the epilimnion and the hypolimnion was only $10 \mu \mathrm{s} / \mathrm{cm}$ (Data report of research vessel Hakken, Lake Biwa Research Institute, Japan, 1999), so effect of nutrient concentrations on water density was ignored in this study.

Shiozu Bay is one of the bays located in the northern part of Lake Biwa and receives hydrological effect from Lake Biwa (Yu et al., 2005). Mean depth and surface area of the bay are about $30 \mathrm{~m}$ and $23 \mathrm{~km}^{2}$, respectively. Sampling point was set at the center of the bay where water depth is $37 \mathrm{~m}$ (Fig.3). Vertical profiles of water temperature, pH, DO and 
other parameters were measured on site with Fine-Scale Profiler (F-probe) every hour. Wind and water current direction and velocity were also measured simultaneously. Long term survey was conducted every two weeks from August, 2002 to December, 2004. Water at depth of 0,5 , “10 or 15", "20 or 25" and $35 \mathrm{~m}$ (5 points) was sampled for measurement of total nitrogen and phosphorus (TN and TP), particulate nitrogen and phosphorus (PN and PP), soluble nitrogen and phosphorus ( $\mathrm{SN}$ and $\mathrm{SP}$ ), ammonium nitrogen $\left(\mathrm{NH}_{4}\right)$, nitrate and nitrite nitrogen $\left(\mathrm{NO}_{3}\right.$ and $\left.\mathrm{NO}_{2}\right)$, phosphate, and chlorophyll-a (Chl.a) by the Standard Method (APHA, AWWA, WEF, 1998). Soluble samples were prepared with $1 \mu \mathrm{m}$ pore size Whatman GFB filter. There were 3 sampling points within the epilimnion ( $0 \mathrm{~m}, 5 \mathrm{~m}$ and " $10 \mathrm{or} 15$ " $\mathrm{m})$ and 2 sampling points within the hypolimnion ("20 or $25 " \mathrm{~m}$ and $35 \mathrm{~m}$ ). The sampling point near the thermocline was determined by the water temperature measurement every time; therefore the depth was not constant.

The North Basin data used here were officially collected at two stations, Imazu Oki and Minamihira Oki in the North Basin (Fig.3), once or twice a month and reported by Shiga Prefecture. The data used here were quoted from Environmental Report for 2003 and 2004 (Shiga Prefecture, 2003; 2004), which are the same year as Shiozu Bay survey. Measurement methods are based on the Japanese National Method which is almost the same as the Standard Method (APHA; AWWA; WEF, 1998).

\section{Results and Discussion}

\section{Thermal Stratification Index}

Time series of Chl.a, Inorg-N, $\mathrm{NO}_{3}$ and SP concentrations in the epilimnion and the hypolimnion in Shiozu Bay are shown in Fig. 4. Inorg-N and $\mathrm{NO}_{3}$ concentrations in the epilimnion were nearly $0 \mathrm{mgN} / \mathrm{L}$ in summer in 2002 and 2004 , but higher than $0.1 \mathrm{mgN} / \mathrm{L}$ in summer in 2003. The difference of Chl.a and SP concentrations between the epilimnion and the hypolimnion was very small. Relationship between TSI and SSI in Shiozu Bay and in the main North Basin of Lake Biwa is shown in Fig. 5. SSI values in Shiozu Bay changed from zero during winter to around $0.3 \mathrm{~kg} \cdot \mathrm{m} / \mathrm{m}^{2} \mathrm{during}$ summer through the 3 years. TSI values in Shiozu Bay varied from zero during winter to around 1 during summer through the 3 years, which means there was no stronger thermocline with TSI of over 1 in the bay. This TSI variation was caused by the upwelling of thermocline, which was related to internal waves and local winds. Occasionally the thermocline of Shiozu Bay reaches the water surface. SSI values at the two points in the main North Basin of Lake Biwa were calculated using the same topographic data. The SSI varied from zero during winter to around $1 \mathrm{~kg} \cdot \mathrm{m} / \mathrm{m}^{2}$ in summer through the 3 years. TSI values in the main North Basin of Lake Biwa changed from zero during winter to around 2 in summer through the 3 years, which means there was stronger thermocline with TSI of over 1. in the North Basin.

Good correlation is shown between the two thermal stratification indices in Shiozu Bay and North Basin, which concluded that both SSI and TSI can be used for discussion on thermal stratification in lakes. Although the ratio of SSI 
to TSI is different between those in Shiozu Bay and in the North Basin of Lake Biwa, SSI is used as the stability index of the whole lake, while TSI is used as the stability index near the thermocline. SSI is suitable to discuss the overall thermal stratification at each point for a long period.

\section{Chemical Stratification Index}

Relationships between SSI and IC-i for Chl.a, Inorg-N, NO 3 , and SP in Shiozu Bay are shown in Fig. 6. IC-Chl.a values were around 1 with some variation when SSI was higher than $0 \mathrm{~kg} \cdot \mathrm{m} / \mathrm{m}^{2}$. Association between IC-Chl.a values and SSI (Fig.6 a) is not clear and it seems that IC-Chl.a was affected by the other factors during spring to early summer. The correlations between SSI and IC-Inorg-N or IC- $\mathrm{NO}_{3}$ values were typical and significant. The chemical stratification was getting stronger (indicated by IC-Inorg-N values and $\mathrm{IC}-\mathrm{NO}_{3}$ values decreasing) when thermal stratification getting stronger. As indicated by the coefficient of determination $\left(\mathrm{r}^{2}\right)$ in the regression in Fig $6 \mathrm{~b}$, and c, SSI explains 74\%, $59 \%$ and $60 \%$ of $\mathrm{IC}^{-\mathrm{NO}_{3}}$ variations in 2002, 2003 and 2004, and explains 77\%, 52\% and 84\% of IC-Inorg-N variations, respectively. The rest part $\left(1-r^{2}\right)$ which can not be explained by SSI should be caused by different biogeochemical processes in 2002, 2003 and 2004. The correlation between SSI and IC-Inorg-N or IC-NO $\mathrm{Na}_{3}$ wa strong that it was possible to make an experience formula to predict IC-Inorg-N or IC-NO $\mathrm{NO}_{3}$ by SSI. It is well known that Inorg-N or $\mathrm{NO}_{3}-\mathrm{N}$ is consumed by phytoplankton production in the epilimnion during thermal stratification period and the stratification itself prevents water and nutrient exchange between the epilimnion and the hypolimnion. Our result showed that the extent of this chemical stratification mechanism is determined by thermal stratification extent. IC-SP values (Fig.6 d) scattered mainly in the range of \pm 1 at low SSI values, and around 0 at higher SSI. The association between IC-SP and SSI is not evident because this parameter is connecting with IC-Chl.a (Fig.6 a).

Relationships between SSI and IC-i for DO, Chl.a, Inorg-N, $\mathrm{NO}_{3}, \mathrm{PO}_{4}$ and $\mathrm{Cl}$ ion $\left(\mathrm{Cl}^{-}\right)$at the official monitoring stations (Imazu Oki and Minamihira Oki) in North Basin of Lake Biwa in 2003 and 2004 are shown in Fig. $7 . \quad$ SSI values changed from 0 during winter to around $1 \mathrm{~kg} \cdot \mathrm{m} / \mathrm{m}^{2}$ during summer. SSI values and IC-i values were clearly and smoothly changed seasonally, because the basin is very large compared with the other bays and does not receive any obvious hydrological effects from bays nor direct effects from the watershed. The correlation between IC-DO values and SSI (Fig.7 a) was not clear because the distribution of DO is determined by phytoplankton growth and organic matter decomposition rather than thermal stratification. IC-Chl.a values (Fig.7 b) had tendency to increase from 0 to the range from around 0 to near 2 at the early phase of the thermal stratification development until around 0.5 $\mathrm{kg} \cdot \mathrm{m} / \mathrm{m}^{2}$, and became steady thereafter which means that thermal stratification is favorite for phytoplankton growth at this early stage of stratification. Similar with the case in Shiozu Bay, the correlations between SSI and IC-Inorg-N or IC-NO 3 values were also significant. The chemical stratification was getting stronger (indicated by IC-Inorg-N values and $\mathrm{IC}-\mathrm{NO}_{3}$ values decreasing) when thermal stratification getting stronger. As indicated by the coefficient of 
determination $\left(\mathrm{r}^{2}\right)$ in the regression in Fig $7 \mathrm{c}$ and d, SSI explains $82 \%$ of IC-Inorg-N variations, and explains $84 \%$ of IC-NO 3 variations respectively. The rest part $\left(1-\mathrm{r}^{2}\right)$ which cannot be explained by SSI should be caused by other biogeochemical processes. IC-PO 4 (Fig.7 e) values decreased dramatically from 0 to near -2 with increase in SSI values until around $0.2 \mathrm{~kg} \cdot \mathrm{m} / \mathrm{m}^{2}$ and were kept steady thereafter. The thermal stratification and phosphate consuming by phytoplankton growth can be responsible for this phenomena in North Basin of Lake Biwa. $\mathrm{Cl}^{-}$(Fig.7 f) is conservative which is not increased or decreased through biogeochemical and/or physical processes in fresh water lakes (Rimmer et al., 2005; Lytras, 2007). Therefore, the $\mathrm{Cl}^{-}$concentrations were constantly homogeneous through water depth $(\mathrm{CU}-\mathrm{Cl}=\mathrm{CL}-\mathrm{Cl})$ and the value of IC-Cl was kept at 0 even during thermal stratification seasons.

The main mechanisms to determine the water quality in Shiozu Bay are primary production and exchange of water by seiche between Shiozu Bay and the North Basin of Lake Biwa (Yu et al., 2005), where eutrophication level was in the middle of oligotrophic and mesotrophic levels under thermal stratification. IC-Chl.a and IC-SP values of around 0 at high SSI in Shiozu Bay means that effects of exchange of water between Shiozu Bay and the North Basin of Lake Biwa is the key mechanism to determine the water quality in Shiozu Bay. Characteristics of IC-Chl.a and IC-SP (IC-PO ${ }_{4}$ ) at high SSI in the main North Basin of Lake Biwa and in Shiozu Bay were totally different. This is possibly due to the difference in their volumes and hydraulic conditions. In Shiozu Bay, the amplitudes of internal Kelvin waves were very large, which impacted the water temperature gradient, and then the TSI and the SSI greatly, while the amplitudes of internal Kelvin waves at the observation station (Fig.3) were small because this point is near the amphidromic point of the internal waves. As discussed here, relationships between thermal stratification and chemical stratification in Shiozu Bay and the North Basin were much different, depending on their water quality formation mechanisms by biogeochemical processes, mixing and exchanging of water body. In conclusion, the proposed indices and their relationships are suitable to discuss thermal stratification and chemical stratification roughly with only a few water quality data available. The advantage of the proposed indices is that they can be easily calculated with at least one set of each water quality data in the epilimnion and the hypolimnion. Furthermore, the SSI can be used to discuss thermal and chemical stratification in detail when the data are plentiful.

\section{REFERENCES}

APHA, AWWA, WEF (1998) Standard methods for the examination of water and wastewater, 20th ed. American Public Health Association, Washington, D.C.

Dunnivant FM (2006) An integrated limnology, microbiology and chemistry exercise for teaching summer lake stratification, nutrient consumption and chemical thermodynamics. American Biology Teacher 68: 424-427 
Elçi Ş (2008) Effects of thermal stratification and mixing on reservoir water quality. Limnology 9: 135-142

Hondzo M, Stefan HG (1996) Long-term Lake Water Quality Predictors. Water Res 30: 2835-2852

Horne AJ, Goldman R (1994) Limnology 2nd ed. McGraw-Hill, New York

Hutchinson GE (1957) Geography, Physics and Chemistry, In A Treatise on Limnology. John Wiley and Sons, New York

Idso SB (1973) On the concept of lake stability. Limnol and Oceanogr 18: 681-683

Imberger J., Hamblin PF (1982) Dynamics of lakes, reservoirs and cooling ponds. Ann Rev Fluid Mech 14: 153-187

Imberger J, Patterson JC (1990) Physical Limnology. Advances in Applied Mechanics 27: 303-455

International Lake Environment Committee (1990) Lake Toba. NEWSLETTER 14

Larson GL, Hoffman RL, McIntire DC, Buktenica MW, Girdner SF (2007) Thermal, chemical, and optical properties of Crater Lake, Oregon. Hydrobiologia 574: 69-84

Lytras E (2007) Developing models for lake management. Desalination 213: 129-134

Michael J.C., Lori W, Kathleen C.P. (2006) Patterns of vertical stratification in a subtropical constructed wetland in south Florida (USA). Ecological Engineering 27: 322-330

Okubo K., S. Nagai, and F. Obayashi (1998) On thermal staircases formed in process of multiple-diffusive convection in lakes. J. Hydrosci. and Hydraulic Engineering 16: 127-136

Rimmer A, Aota Y, Kumagai M, Eckert W (2005) Source Chemical stratification in thermally stratified lakes: A chloride mass balance model. Limnol and Oceanogr 50: 147-157

Schmidt W (1928) Uber die Temperatur- und Stabilitatsverhaltnisse von Seen. Geogr Ann 10: 145-177

Shiga Prefecture (2003) Environmental Report for 2003, Shiga, Japan (in Japanese)

Shiga Prefecture (2004) Environmental Report for 2004, Shiga, Japan (in Japanese)

Talling JF (2006) Interrelated seasonal shifts in acid-base and oxidation-reduction systems that determine chemical stratification in three dissimilar English lake basins. Hydrobiologia 568: 275-286

Turner J S (1973) Buoyancy effect in fluid. Cambridge University Press, New York, NY 
Yu H, Jiao C, Kishimoto N, Hidaka T, Tsuno H (2005) Isotherm surface method for estimating water and nutrient exchange between bays and major basins of large lakes (in Japanese). J Environ Syst Eng 804: 23-32

Wetzel RG (2001) Limnology: Lake and River Ecosystems 3rd ed. Academic Press, San Diego, CA 
Figure legends

Figure 1 Relationship between $\ln (\mathrm{CU}-\mathrm{i} / \mathrm{CL}-\mathrm{i})$ and the newly proposed chemical stratification index of IC-i

Figure 2 Correlation concept map between TSI and SSI, and IC-i

Figure 3 Study sites in Lake Biwa, Shiga Prefecture, Japan

Figure 4 Time series of water quality in Shiozu Bay: a time series of Chl.a; $\mathbf{b}$ time series of Inorg-N; $\mathbf{c}$ time seriesof

$\mathrm{NO}_{3}$; $\mathbf{d}$ time series of SP. The epilimnion value and the hypolimnion velue are average values among $0 \mathrm{~m}, 5 \mathrm{~m}$ and $10 \mathrm{~m}$ depth and average values between $20 \mathrm{~m}$ and $35 \mathrm{~m}$ depth, respectively

Figure 5 Time series of TSI and SSI, and relationship between TSI and SSI values: a time series of TSI and SSI in Shiozu Bay; b relationship between TSI and SSI values in Shiozu Bay; c time series of TSI and SSI in Imazu Oki(Imazu) and Minamihira Oki(Minami); d relationship between TSI and SSI values in Imazu Oki(Imazu) and Minamihira Oki(Minami)

Figure 6 Relationships between SSI and IC-i in Shiozu Bay: a relationship between SSI and IC-Chl.a; b relationship between SSI and $\mathrm{IC}-\mathrm{NO}_{3}$; $\mathbf{c}$ relationship between SSI and IC-Inorg-N; $\mathbf{d}$ relationship between SSI and IC-SP

Figure 7 Relationships between SSI and IC-i in Imazu Oki(Imazu) and Minamihira Oki(Minami): a relationship between SSI and IC-Chl.a; b relationship between SSI and IC-NO ; $_{3}$ c relationship between SSI and IC-Inorg-N; d relationship between SSI and IC-PO $\mathrm{PO}_{4}$ e relationship between SSI and IC-DO; f relationship between SSI and IC-Cl 
Figure 1

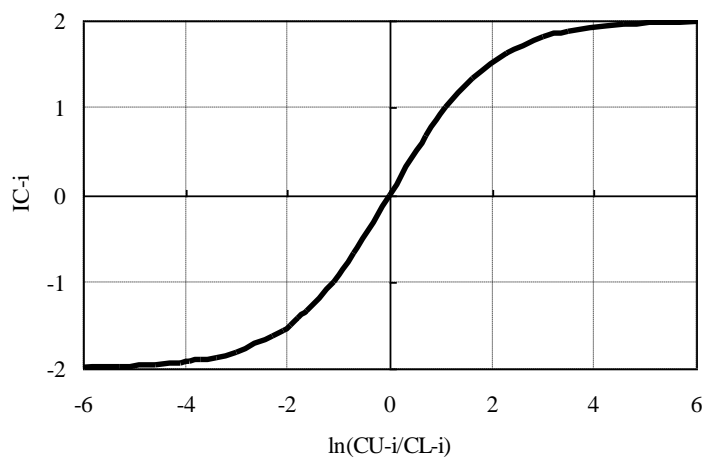


Figure 2

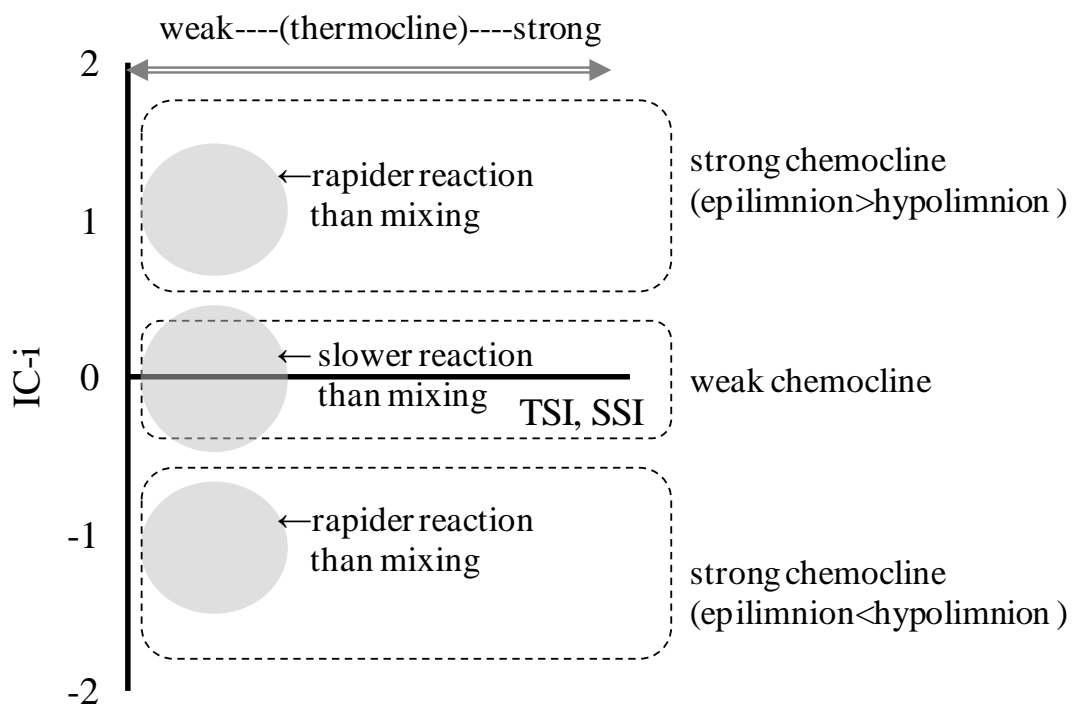


Figure 3

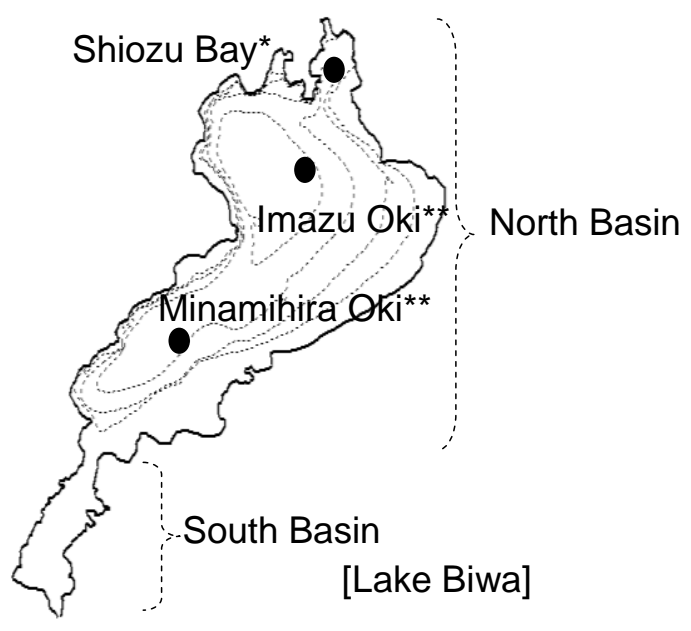

* station of this research $(2002,2003,2004)$,

** stations by Shiga Pref. (2002, 2003, 2004), 
Figure 4
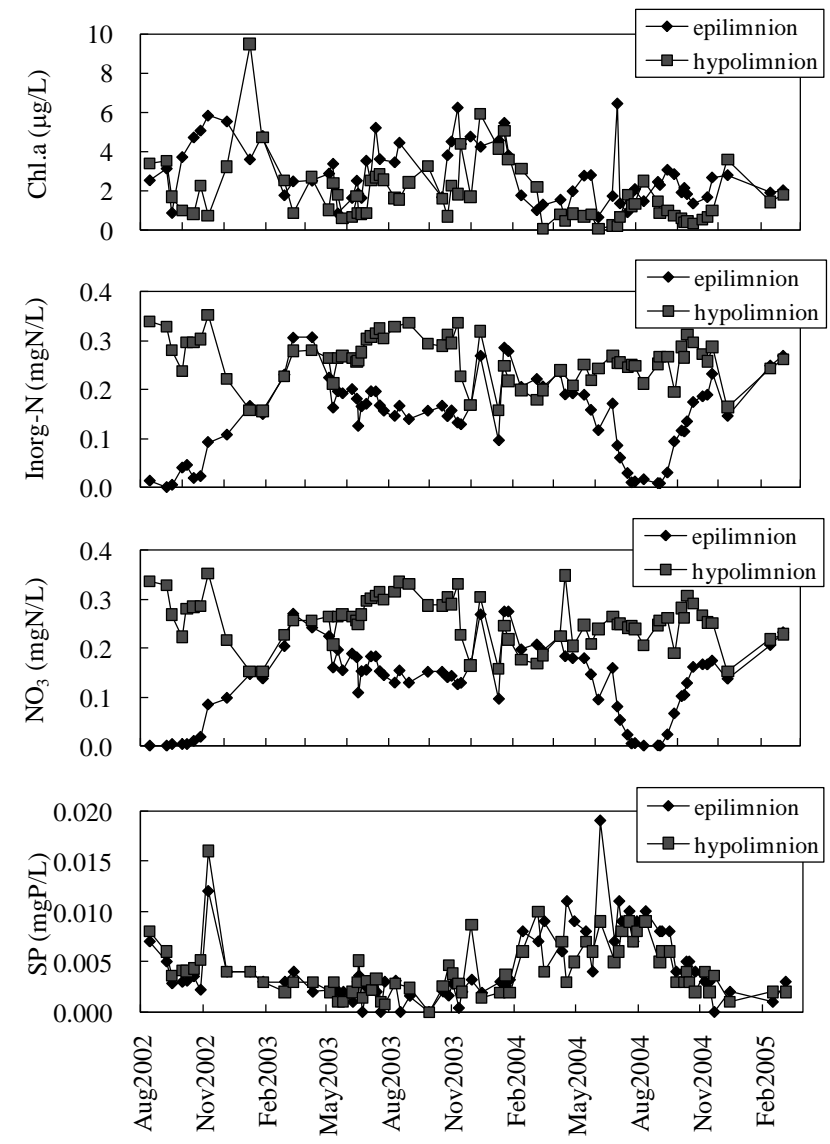
Figure 5
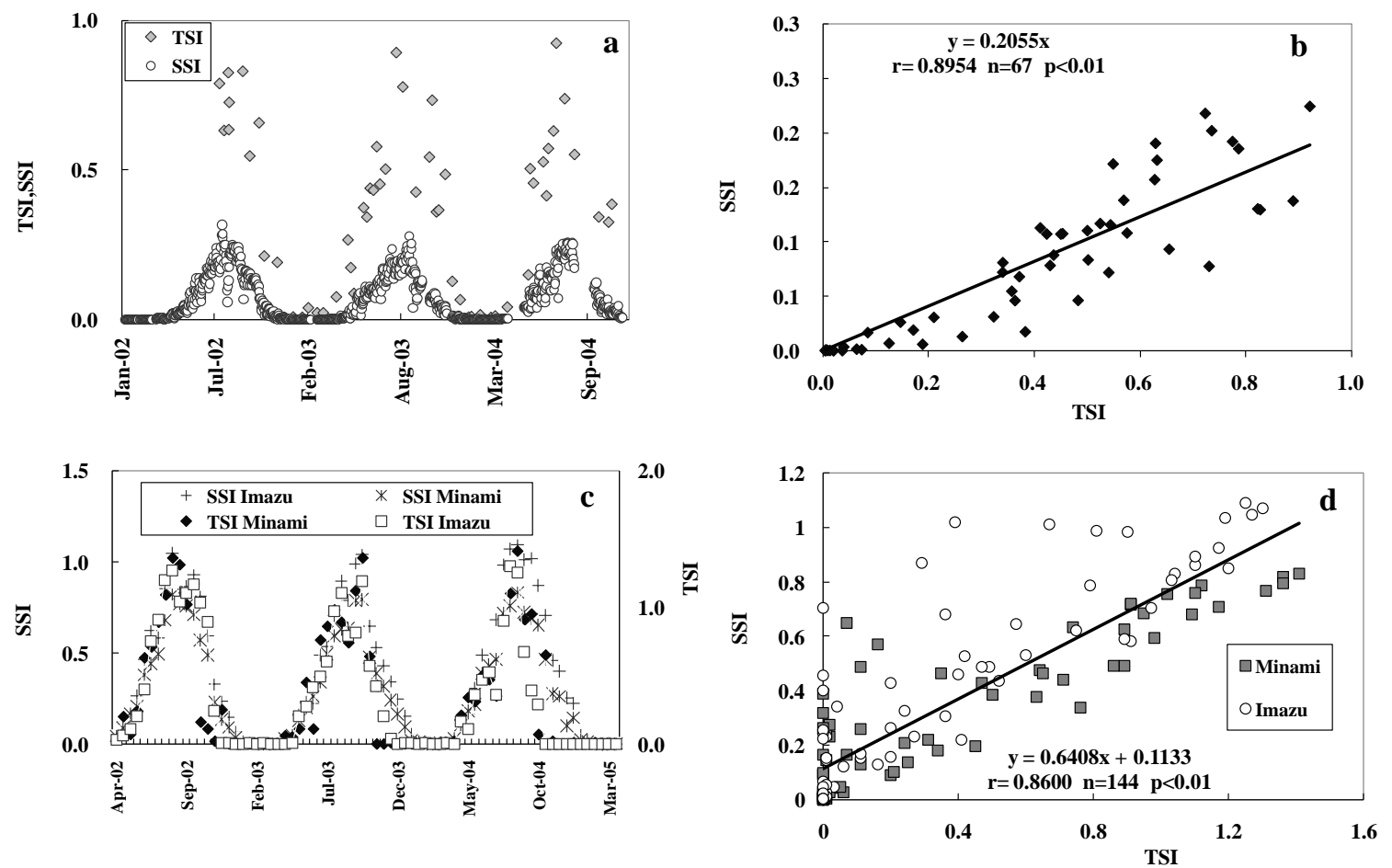
Figure 6
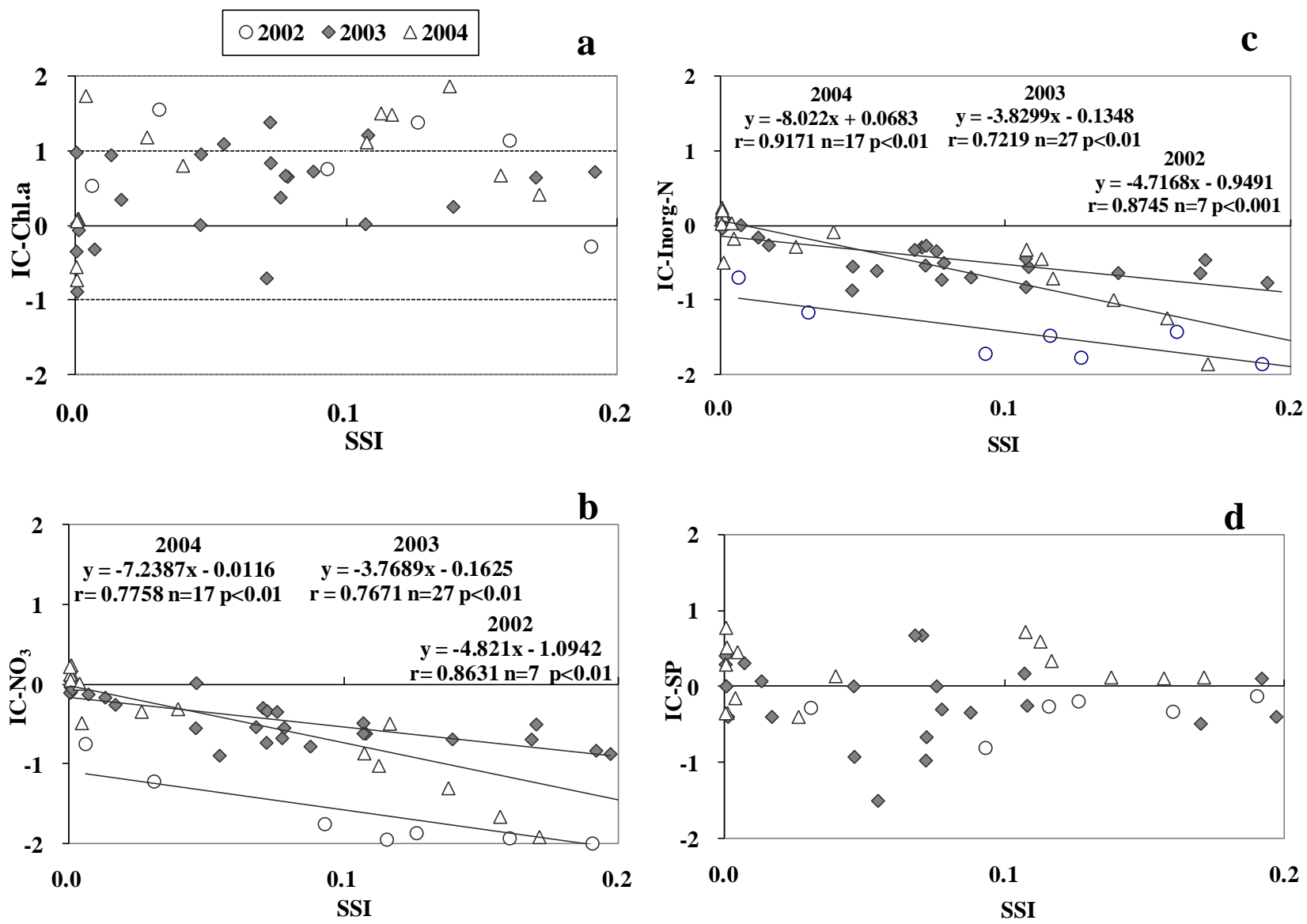
Figure 7
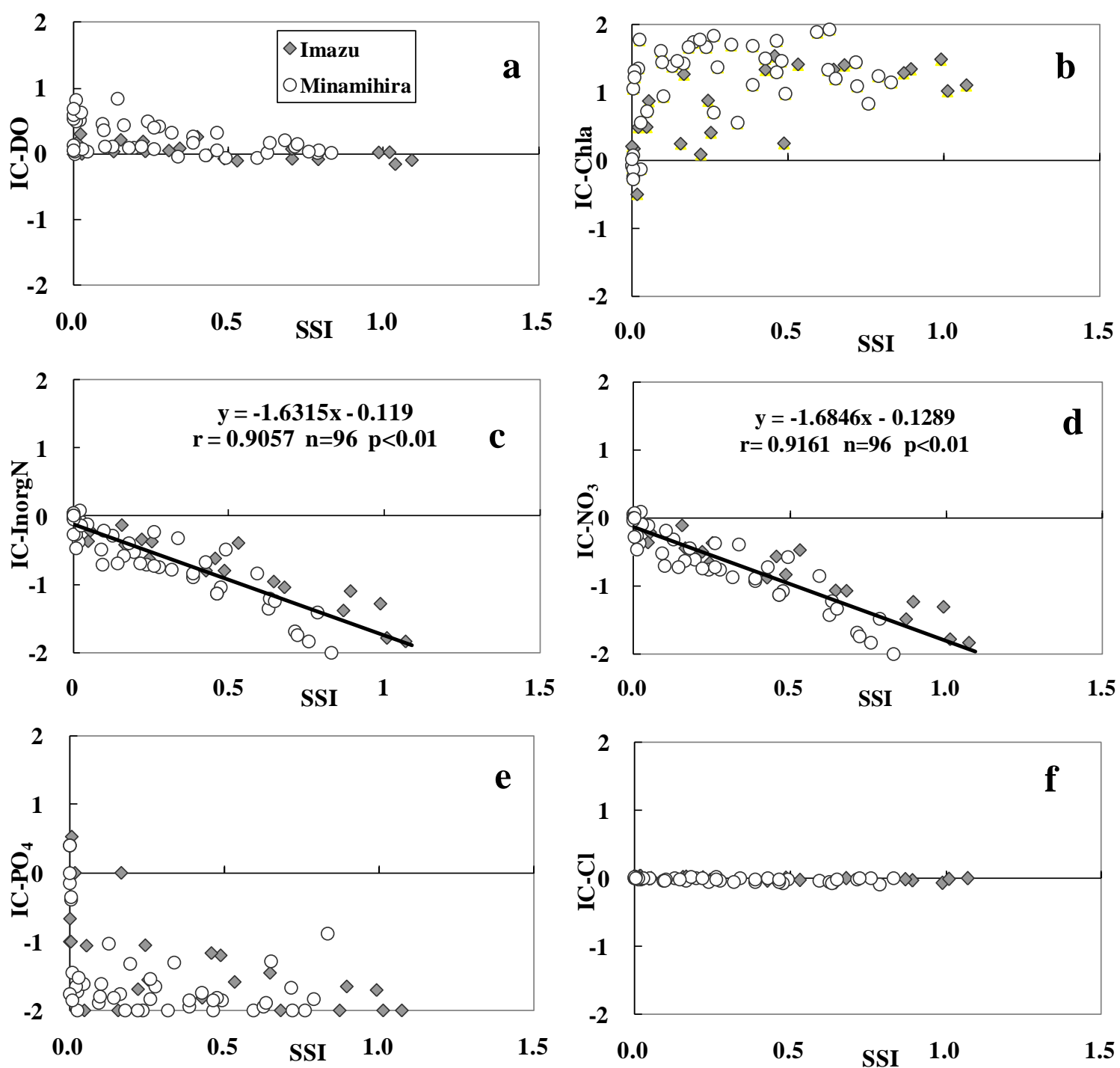